\title{
Early phase of COVID-19 quarantine impacted insomnia symptoms in Turkish families
}

Huri Seval Gönderen Çakmak*

Cankiri Karatekin University, Eldivan Vocational School of Health Services Cankiri - Turkey.
*Corresponding author: Huri Seval Gönderen Çakmak

E-mail: sevalgonderen@hotmail.com

Received: April 26, 2021;

Accepted: October 4, 2021.

\begin{abstract}
Quarantine and isolation are the most important public health measures used to prevent the transmission of infectious diseases among individuals. Quarantine and social isolation cause some health problems, such as depressive symptoms, sleep disturbances, anxiety, irritability, feeling of loneliness, helplessness, and trauma and post-traumatic stress symptoms. In this study, we aimed to examine early phase of COVID-19 quarantine impacted insomnia symptoms in Turkish families. The population of the study comprised students attending the Department of Healthcare Services of Eldivan Health Vocational School at Çankırı Karatekin University and their families. In total, 564 students and their families completed online surveys. Data was collected with Google forms. Snowball sampling was used as the data collection method. Female participants, those who gained weight during home quarantine, those who put their phones under their pillow or at the bedside and in another room, and those who used a phone or tablet before sleeping were found to have significantly more insomnia compared to others. The mean day of uninterrupted home quarantine was higher for participants experiencing insomnia $(p<0.05)$. This study showed that individuals experienced sleep problems during the home quarantine.
\end{abstract}

Keywords: Insomnia; COVID-19; Sleep; Sleep Stages. 


\section{INTRODUCTION}

After the World Health Organization (WHO) declared COVID-19 to be a pandemic, schools, restaurants, entertainment centers, shopping malls, factories, and hairdressers were closed in most countries to prevent spread of the virus. In Turkey, young people between 0-20 years and older adults over 65 years were subjected to restrictions about leaving home after the decision of the Ministry of Health Pandemic Science Board. People between the ages of 20-65 can only go out for a short time in compulsory situations (market, emergency situations, etc.). Curfews were declared in some of the big cities where a significant number of cases were reported. Quarantine and isolation are the most important public health measures used to prevent the transmission of infectious diseases among individuals. Although people had to stay more in their homes and their living spaces were restricted, COVID-19 positive cases decreased thanks to these measures ${ }^{1,2}$. In addition, the quarantine process digitalized people's social activities and habits, changing both melatonin mechanism and sleep rhythm ${ }^{3}$.

Recent studies found that quarantine and social isolation cause some health problems, such as depressive symptoms, sleep disturbances, anxiety, irritability, feelings of loneliness, helplessness, and trauma and posttraumatic stress symptoms ${ }^{1,2,4-7}$. A study conducted in China during the COVID-19 pandemic also found that about $35 \%$ of those surveyed showed psychological distress ${ }^{8}$. In a study conducted with 129 people with severe acute respiratory syndrome in Canada, those who were quarantined for more than 10 days showed significantly higher post-traumatic stress symptoms than those who were quarantined for less than 10 days. In addition, $28.9 \%$ of individuals had symptoms of post-traumatic stress disorder and $31.2 \%$ had symptoms of depression . In a study conducted by Shi et al. during the pandemic in China, the rates of mental health symptoms among the respondents during the COVID-19 pandemic were found to be $27.9 \%$ for depression, $31.6 \%$ for anxiety, $29.2 \%$ for insomnia and $24.4 \%$ for acute stress ${ }^{10}$.

It should be noted that sleep is an essential determinant of the general health status of an individual, as well as contributing to the functioning of the defense mechanism against infections. Individuals with quarantine or limited social relationships are known to experience many health problems related to insomnia ${ }^{11-13}$.

Impairment of sleep quality not only ruins the general health status of an individual but also makes it difficult to cope with the COVID-19 infection due to changing the immune response ${ }^{14}$. There is solid evidence to suggest the role of sleep in strengthening immunity ${ }^{15}$. In the study by Hajak and Group (2001), insomnia patients were found to visit hospital, to suffer tics, and to be medicated more than their healthy counterparts. In addition, insomnia adversely affects patients' quality of life ${ }^{16}$.
Sleep plays a fundamental role in mental and physical health. Adequate sleep time and quality are essential to cope with major vital events such as the COVID-19 pandemic ${ }^{17}$. Stress sleep problems are common, and people with stress-related sleep disorder have a higher risk of developing chronic insomnia ${ }^{12}$. In a study by Kocevska et al., $20 \%$ of individuals with good sleep quality simultaneously had seriously decreased sleep quality after quarantine. Changes in sleep quality throughout the pandemic were associated with negative affect and anxiety ${ }^{18}$. Similarly, in a study conducted in France, sleep problems were observed in individuals during the closures due to COVID-1919. A study in China also found that low sleep quality was quite common in individuals returning to work during COVID-1920. A study conducted in Norway found that anxiety and depressive symptoms were associated with sleep disorders ${ }^{21}$. Insomnia is generally associated with depression, anxiety, and mental disorders ${ }^{22}$.

Although the world and Turkey initiated the normalization process from June 2020, it is prudent to say that people have not fully restored their habits from before the pandemic, such as spending time in shopping malls and playgrounds and going to the cinema. The relevant authorities, such as the World Health Organization, state that COVID-19 outbreak measures may continue for 1 to 2 years, which means that a chronic process awaits society after the acute process. Quarantine is generally an unpleasant experience. Separation from beloved ones, restrictions on freedom, uncertainty about illness, and boredom can have dramatic effects on sleep quality. For this reason, health professionals, who lead the way in maintaining and supporting public and individual health, should evaluate the situation and develop alternative interventions that can be applied at home both for the protection of the general health status of individuals and for effective interventions against COVID-19.

In this study, the aim was to determine early phase of COVID-19 quarantine impacted insomnia symptoms in Turkish families.

\section{MATERIAL AND METHODS}

\section{Study design and Participants}

This study was conducted as a descriptive crosssectional study. The population of the study included students attending the Department of Healthcare Services of Eldivan Health Vocational School at Çankırı Karatekin University and their families. The study was collected by Google forms due to pandemic conditions. The study link was sent to the mobile phones of students through the health care services department. Those who accepted participation in the study were asked to fill in the study link and then send it to their families. In this way, the snowball sampling method was applied. 
A total of 250 students were enrolled in the department, but the population was calculated as 750 people, considering that students would send study links to at least 3 family members. The inclusion criteria were being 18 years of age and over and accepting participation in the study. Overall, 564 people ( $75 \%$ of the universe) participated in the study.

\section{Data collection}

Due to the COVID-19 outbreak, the data were gathered through online survey forms between June 0830,2020 . The survey link was sent to the students and their family members via SMS, and they were asked to fill in the survey forms. Participation in the study was on a totally voluntary basis.

\section{Data Collection Tools}

\section{Demographic Information Form}

Considering the previous research, a demographic information form was created by the researcher to identify the socio-demographic characteristics of the participants ${ }^{3}$, 14, 23-27. This form contained 11 questions related to age, gender, weight, educational attainment, use of phone or tablet, and smoking.

\section{Bergen Insomnia Scale}

The scale was developed by Pallesen et al. in 2008 based on official and clinical diagnostic criteria for insomnia. The Bergen Insomnia Scale was created on the basis of DSM-4 diagnostic criteria, but it also meets the DSM-5 diagnostic criteria. The scale consists of six questions measuring different symptoms of insomnia. Using the 8-point Likert-type scale, respondents express the number of days that they experienced sleep problems over the past month. While the lowest score that can be obtained from the scale is 0 , the highest score is 42 . Higher scores indicate more sleep and daytime fatigue. Getting a score of 3 or more from at least one of the first three questions of the scale and additionally getting a score of three or more from at least one of the last two questions can be stated as insomnia. Pallesen et al. (2008) administered the scale to three different sample groups: students, communities, and patients. While a two-factor structure was found in the student and patient samples, the scale showed a single-factor structure in the community sample. In the original study conducted with adults, the internal consistency coefficient of the scale was found to be $\alpha=0.87$, and its test-retest reliability coefficient was calculated as $r=0.77$. According to DSM-5 diagnostic criteria, 3 or more points from at least one of the first three questions or one of the last two questions indicate insomnia. In recent studies, the fourth question on the scale, "How many days a week do you feel unable to rest enough after waking up" was indicated to be related to sleep quality; therefore, it should be evaluated within DSM-5 criteria ${ }^{28}$.

The validity and reliability studies of the Turkish version of the Bergen Insomnia Scale were performed by Bay, Yalçın, and Ergün (2018). A two-factor structure was found in the Turkish version of the scale administered to adult individuals. Cronbach's Alpha reliability coefficient was calculated as 0.85 for the daytime symptoms subscale, 0.80 for the nighttime symptoms sub-scale and 0.85 for the total scale ${ }^{29}$.

\section{Statistical analysis}

The data about demografic variables are presented as numbers and percentages. Fisher's Exact Test, Pearson's Chi Square Test, and Yates Correction were used for categorical variables. The Shapiro-Wilk test was used to check the normality of continuous variables, and the not normally distributed data were analyzed with the MannWhitney U Test (nonparametric test). The statistical significance level was accepted as $\mathrm{p}<0.05$.

\section{RESULTS}

The mean age of the participants was $28.13 \pm 0.49$ years (min: $18 / \max : 90$ ). While $71.1 \%$ of the participants were female, $66.5 \%$ were single. It was found that $66.3 \%$ of the individuals were university students, and $82.8 \%$ did not have any chronic diseases. Twenty-five percent of the participants lived alone, $32.4 \%$ lived with their parents, and $41.7 \%$ lived with their children and spouses. While $72.0 \%$ did not smoke, $42.9 \%$ of the participants stated that they gained weight during quarantine. Sixtyfour percent stated that they kept their phone under their pillow/at the bedside, while $83.3 \%$ stated that they used a tablet/phone before sleeping. The results revealed that $64.7 \%$ of the participants had insomnia (Table 1).

The mean age of the participants was $28.13 \pm 11.56$ years, the mean days of uninterrupted home quarantine was $34.42 \pm 31.13$, and the mean scores of the participants on the scale was $18.26 \pm 10.29$ (Table 2). The findings suggest that there was no statistically significant difference between insomnia and age, educational attainment, smoking status, and who the participants lived during the quarantine ( $p>0.05)$. In addition, female participants $(\mathrm{p}=0.001)$, those who gained weight during the home quarantine $(\mathrm{p}=0.031)$, those who put their phones under the pillow or at the bedside $(\mathrm{p}=0.016)$ and in another room $(\mathrm{p}=0.016)$, and those who used a phone or tablet before sleeping $(\mathrm{p}=0.020)$ were found to have significantly higher levels of insomnia than others. According to the findings on the scale, there was a statistically significant difference between interrupted quarantine and uninterrupted quarantine (p: 0.012) (Table 3). The mean days of uninterrupted home quarantine was higher for participants experiencing insomnia. 
Table 1. Socio-demographic characteristics and insomnia findings of the participants.

\begin{tabular}{|c|c|c|}
\hline Variable & Number (n:564) & $\%$ \\
\hline Age & \multicolumn{2}{|c|}{$28.13 \pm 0.487$ (min:18/max:90) } \\
\hline \multicolumn{3}{|l|}{ Gender } \\
\hline Female & 401 & 71.1 \\
\hline \multicolumn{3}{|l|}{ Marital status } \\
\hline Single & 375 & 66.5 \\
\hline Literate & 6 & 1.1 \\
\hline Primary school graduate & 46 & 8.2 \\
\hline High school graduate & 88 & 15.6 \\
\hline University student & 374 & 66.3 \\
\hline University graduate & 50 & 8.9 \\
\hline \multicolumn{3}{|l|}{ Who do you live with at home? } \\
\hline Mother - father & 183 & 32.4 \\
\hline Children-spouse & 235 & 41.7 \\
\hline Alone & 146 & 25.9 \\
\hline \multicolumn{3}{|l|}{ Smoking status } \\
\hline Yes & 144 & 25.5 \\
\hline No & 406 & 72.0 \\
\hline I haven't been smoking for the past 6 months & 14 & 2.5 \\
\hline \multicolumn{3}{|l|}{ Smoking during quarantine? n: 144} \\
\hline Increased & 28 & 19.44 \\
\hline Decreased & 22 & 15.27 \\
\hline Under my pillow / at my bedside & 361 & 64.0 \\
\hline Away from my bed & 157 & 27.8 \\
\hline In another room & 46 & 8.2 \\
\hline \multicolumn{3}{|c|}{ Do you use a phone/tablet before going to sleep? } \\
\hline Yes & 470 & 83.3 \\
\hline No & 94 & 16.7 \\
\hline \multicolumn{3}{|l|}{ Insomnia finding } \\
\hline Insomnia & 365 & 64.7 \\
\hline No insomnia & 199 & 35.3 \\
\hline
\end{tabular}

Table 2. Mean, minimum, and maximum values for age, uninterrupted home quarantine, and the scale.

\begin{tabular}{ll|l|l}
\hline & M \pm SD & Min. & Max. \\
\hline Age & $28.13 \pm 11.563$ & 18 & 90 \\
Home quarantine & $34.42 \pm 31.127$ (days) & 1 & 120 \\
Scale score & $18.26 \pm 10.288$ & 0 & 42 \\
\hline
\end{tabular}


Table 3. Insomnia according to socio-demographic characteristics of the participants.

\begin{tabular}{|c|c|c|c|c|c|c|}
\hline \multirow{2}{*}{ Variable } & & \multicolumn{5}{|c|}{ Bergen Insomnia Scale } \\
\hline & & & & & & \multirow{3}{*}{ Statistics } \\
\hline & & \multirow{2}{*}{$\begin{array}{c}\text { Insomnia } \\
\mathrm{n}\end{array}$} & \multicolumn{3}{|c|}{ No insomnia } & \\
\hline & & & $\%$ & $\mathrm{n}$ & $\%$ & \\
\hline \multicolumn{7}{|l|}{ Age groups } \\
\hline & $18-24$ years & 220 & $68.1 \%$ & 103 & $31.9 \%$ & $\chi^{2}: 5.627^{*}$ \\
\hline & 25-34 years & 57 & $56.4 \%$ & 44 & $43.6 \%$ & \\
\hline & $35-44$ years & 49 & $60.5 \%$ & 32 & $39.5 \%$ & $\mathrm{p}=0.344$ \\
\hline & $45-55$ years & 25 & $64.1 \%$ & 14 & $35.9 \%$ & \\
\hline & 56-64 years & 8 & $72.7 \%$ & 3 & $27.3 \%$ & \\
\hline & 65 years and over & 6 & $66.7 \%$ & 3 & $33.3 \%$ & \\
\hline \multicolumn{7}{|l|}{ Gender } \\
\hline & Female & 277 & $69.1 \%$ & 124 & $30.9 \%$ & $\chi^{2: 11.556^{* *}}$ \\
\hline & Male & 88 & $54.0 \%$ & 75 & $46.0 \%$ & $\mathrm{p}=0.001$ \\
\hline & Literate & 5 & $83.3 \%$ & 1 & $16.7 \%$ & $\chi^{2: 8.112^{*}}$ \\
\hline \multirow{2}{*}{\multicolumn{7}{|c|}{$\begin{array}{l}\text { Educational } \\
\text { Attainment }\end{array}$}} \\
\hline & & & & & & \\
\hline & $\begin{array}{l}\text { Primary school } \\
\text { graduate }\end{array}$ & 31 & $67.4 \%$ & 15 & $32.6 \%$ & $\mathrm{p}=0.088$ \\
\hline & $\begin{array}{l}\text { High school } \\
\text { graduate }\end{array}$ & 48 & $54.5 \%$ & 40 & $45.5 \%$ & \\
\hline & University student & 253 & $67.6 \%$ & 121 & $32.4 \%$ & \\
\hline & University graduate & 28 & $56.0 \%$ & 22 & $44.0 \%$ & \\
\hline \multicolumn{7}{|l|}{$\begin{array}{l}\text { Who do you live } \\
\text { with at home? }\end{array}$} \\
\hline & Mother - father & 123 & $67.2 \%$ & 60 & $32.8 \%$ & $\chi^{2: 0.817^{* *}}$ \\
\hline & Children-spouse & 148 & $63.0 \%$ & 87 & $37.0 \%$ & \\
\hline & Alone & 94 & $64.4 \%$ & 52 & $35.6 \%$ & $\mathrm{p}=0.665$ \\
\hline \multicolumn{7}{|l|}{ Smoking status } \\
\hline & Yes & 87 & $60.4 \%$ & 57 & $39.6 \%$ & $\chi 2: 1.589 *$ \\
\hline & No & 269 & $66.3 \%$ & 137 & $33.7 \%$ & \\
\hline & $\begin{array}{l}\text { I haven't been } \\
\text { smoking for the past } \\
6 \text { months }\end{array}$ & 9 & $64.3 \%$ & 5 & $35.7 \%$ & $\mathrm{P}=0.452$ \\
\hline \multicolumn{7}{|c|}{$\begin{array}{l}\text { Smoking during } \\
\text { quarantine? n: } 144\end{array}$} \\
\hline & Increased & 22 & 78.57 & 6 & 21.42 & $\chi^{2: 6.790 * *}$ \\
\hline & Decreased & 14 & 63.63 & 8 & 36.36 & $\mathrm{p}=0.147$ \\
\hline & Unchanged & 52 & 55.31 & 42 & 44.68 & \\
\hline \multicolumn{7}{|c|}{ Weight Status } \\
\hline \multicolumn{7}{|c|}{ During Quarantine } \\
\hline & Increased & 168 & $69.4 \%$ & 74 & $30.6 \%$ & $\chi^{2: 6.925^{* * *}}$ \\
\hline & Decreased & 76 & $67.3 \%$ & 37 & $32.7 \%$ & \\
\hline & Unchanged & 121 & $57.9 \%$ & 88 & $42.1 \%$ & $\mathrm{p}=0.031$ \\
\hline \multicolumn{7}{|c|}{$\begin{array}{l}\text { Where do you put } \\
\text { your phone/tablet } \\
\text { while sleeping? }\end{array}$} \\
\hline & $\begin{array}{l}\text { Under my pillow / } \\
\text { at my bedside }\end{array}$ & 31 & $67.4 \%$ & 15 & $32.6 \%$ & $\chi^{2: 8.264^{* * *}}$ \\
\hline & Away from my bed & 247 & $68.4 \%$ & 114 & $31.6 \%$ & $\mathrm{p}=0.016$ \\
\hline & In another room & 87 & $55.4 \%$ & 70 & $44.6 \%$ & \\
\hline \multirow{2}{*}{$\begin{array}{l}\text { Do you use a } \\
\text { phone/ tablet } \\
\text { before going to } \\
\text { sleep? }\end{array}$} & Yes & 315 & $67 \%$ & 155 & $33 \%$ & $\chi^{2: 7.814^{*}}$ \\
\hline & No & 50 & $53.8 \%$ & 43 & $46.2 \%$ & $\mathrm{p}=0.02$ \\
\hline \multirow{2}{*}{\multicolumn{2}{|c|}{ Uninterrupted quarantine time (days) }} & M & SD & M & SD & Z: -2.512 \\
\hline & & 34.48 & 31.66 & 30.29 & 29.72 & p: 0.012 \\
\hline
\end{tabular}

*Fisher's Exact Test, ** Pearson's Chi Square Test, ***Yates Correction, Z= Mann-Whitney U Test. 


\section{DISCUSSION}

This study, using data collected from Turkish individuals during the COVID-19 pandemic, aimed to determine early phase of COVID-19 quarantine impacted insomnia symptoms in Turkish families.

In the current study, $64.7 \%$ of the individuals participating in the study experienced insomnia according to the Bergen insomnia scale. Similarly, in a study conducted with university students, it was determined that $59.3 \%$ of the students experienced insomnia ${ }^{30}$. In a study conducted in the USA, approximately $35 \%$ of Americans complained of insomnia at least once in a year ${ }^{31}$. During the pandemic period, insomnia was reported in $37.6 \%$ of the Greek population ${ }^{32}$. In Italy, $57 \%$ of individuals reported low sleep quality during the pandemic ${ }^{33}$. The reason for this difference may be the cultural structure and the home quarantine processes experienced during the pandemic differ from country to country.

In the current study female participants were found to suffer more insomnia than males $(\mathrm{p}=0.001)$. The literature suggests that insomnia is seen more frequently in females, the divorced, the unemployed, older adults, and individuals with poor educational background and low socioeconomic status ${ }^{24,34,35}$. In the study by Parlapani et al., women reported significantly higher levels of fear associated with COVID-19, more severe depressive symptoms, sleep disturbances, and higher levels of intolerance to uncertainty ${ }^{36}$. We can attribute the higher incidence of insomnia in women to causes such as the perception of stress and inactivity ${ }^{30}$. Also, previous research has found that people with depression and anxiety are very likely to experience insomnia. The fact that the female gender is more prone to depression and anxiety contributes to the possibility of insomnia ${ }^{37,38}$.

In our study, the reason for insomnia in more than half of the participants can be explained by the home quarantine due to the COVID-19 outbreak. A study suggested that the more time adults spent watching TV and using the internet before sleeping, the more likely they were to report poor sleep ${ }^{39}$. In another study, the use of a computer or mobile phone in bedroom was associated with poor sleeping habits, but the use of digital tools in the bedroom was unrelated to signs of insomnia ${ }^{40}$. In the current study, it was observed that those who put their phones or tablets under the pillow or at the bedside and those using a phone or tablet before sleeping experienced more insomnia than others. Demirer et al. found the rate of insomnia was significantly higher for those who use phones in bed than those who do not, and using a phone in bed increased the risk of insomnia 1.6 times ${ }^{30}$.

Social isolation during the pandemic has undoubtedly increased people's habits of using digital tools. This increase also affects secretion of melatonin due to factors such as exposure to light at night and late bedtimes. Melatonin can reduce immune suppression caused by chronic stress and sleep deprivation ${ }^{41}$.

In China, insomnia in the general population was assessed at $15 \%$, and the widespread use of new media such as computers and smartphones in young adults was associated with an increased risk of insomnia ${ }^{42}$. The relationship between smoking and sleep disturbance is well known. Smoking is associated with shorter sleep time and increased difficulty falling asleep, as well as other sleep disorders ${ }^{26,}{ }^{43}$. Nevertheless, there was no statistically significant difference between smokers and non-smokers regarding insomnia $(\mathrm{p}=0.452)$, which was also the case for those who increased smoking during the home quarantine and those who did not $(\mathrm{p}=0.147)$. In the current study, those who gained weight during the home quarantine had more impaired sleep than others $(\mathrm{p}=0.031)$. Weight increase was observed in $42.9 \%$ of the participants. Zachary et al. (2020) in a study found roughly $22 \%$ of adults reported gaining weight during the COVID-19 outbreak. During this period, eating due to lack of sleep, decreased physical activity, and eating in response to stress are behaviors related to weight gain during quarantine. Just as a lack of sleep increases eating, weight gain also causes sleep problems.

Suffering from insomnia increased significantly as the duration of uninterrupted quarantine increased $(p=0.012)$. Although the duration of quarantine is not always definite, a study showed that those who were quarantined for more than 10 days showed significantly higher post-traumatic stress symptoms than those quarantined for less than 10 days ${ }^{9}$. Some studies showed that longer quarantine times were associated with poor mental health, especially with post-traumatic stress symptoms ${ }^{44,45}$. Therefore, prolongation of the quarantine time may affect habits, eating behaviors, and internet and substance use. It was shown in a study that isolated individuals had high levels of anxiety and stress and low sleep quality. However, being relaxed and sleeping well are all required for good psychological health of individuals isolated during the epidemic. Additionally, social capital levels can affect mental health and sleep quality. Social capital includes social trust, belonging, and social participation. During 14-day self-isolation due to the COVID-19 outbreak in central China, increased social capital improved sleep quality by reducing anxiety and stress $^{27}$. In addition, social interactions can reduce negative emotions and improve mood. It was concluded in a study that social support for healthcare staff positively affected their sleep quality. ${ }^{46}$.

Although sleep problems due to quarantine during COVID-19 in France began to return to normal after closure, improvements in sleep problems decreased especially in those exposed to negative news about the epidemic $^{19}$. In a study conducted in Spain, $39.7 \%$ of 
individuals reported lower quality sleep during COVID-19 and this had a positive correlation with $\mathrm{BMI}{ }^{47}$.

\section{LIMITATIONS}

The current study had several limitations. Firstly, insomnia symptoms were evaluated according to the self-report of individuals. Secondly, we do not know the anxiety and depression levels of individuals before the pandemic. If individuals have pre-pandemic anxiety and depression, they may be more likely to experience insomnia symptoms.

\section{STRENGTHS}

Moreover, participants experience of insomnia was determined only based on their statements. This study is the first nursing study to evaluate early phase of COVID-19 quarantine impacted insomnia symptoms in Turkish families. This study can serve as a basis for evaluating sleepiness and sleep habits of individuals during and after the quarantine period.

\section{CONCLUSION}

To the best of our knowledge, this is the first study investigated early phase of COVID-19 quarantine impacted insomnia symptoms in Turkey. This study showed that individuals experienced sleep problems during the home quarantine. Therefore, the results of the study form a robust ground for nursing interventions so that individuals can maintain healthy habits in spite of sudden lifestyle changes during a pandemic. During the pandemic, individuals can be followed up with telenursing practices so that they can maintain their healthy sleep habits. In addition, individuals can be directed to detox for internet and computer use.

\section{ACKNOWLEDGEMENTS}

Author would like to thank those who participated in the study.

\section{CONFLICT OF INTEREST}

Author declares no conflicts of interest.

\section{ETHICAL STATEMENTS}

The present study was approved by the Ethics Committee of Çankırı Karatekin University (Decision Number: 2020/225, Date: June 8, 2020). Online informed consent was obtained from the participants. The information obtained was kept completely confidential and used only for research purposes.

\section{REFERENCES}

1. Brooks SK, Webster RK, Smith LE, et al. The psychological impact of quarantine and how to reduce it: rapid review of the evidence. The Lancet. 2020.

2. Hossain MM, Sultana A, Purohit N. Mental health outcomes of quarantine and isolation for infection prevention: A systematic umbrella review of the global evidence. Available at SSRN 3561265. 2020.

3. Chatterjee P, Yatnatti SK. Intergenerational Digital Engagement: A Way to Prevent Social Isolation During the COVID-19 Crisis. Journal of the American Geriatrics Society. 2020.

4. Erdoğan A, Hocaoğlu Ç. Enfeksiyon hastalıklarının ve pandeminin psikiyatrik yönü: Bir gözden geçirme. Klinik Psikiyatri Dergisi. 2020:23.

5. Sprang G, Silman M. Posttraumatic stress disorder in parents and youth after health-related disasters. Disaster medicine and public health preparedness. 2013;7(1):105-110.

6. Jeong H, Yim HW, Song Y-J, et al. Mental health status of people isolated due to Middle East Respiratory Syndrome. Epidemiology and health. 2016;38.

7. Rodrigues Aguilar AC, Frange C, Huebra L, Dias Gomes AC, Tufik S, Santos Coelho FM. The effects of the COVID-19 pandemic on patients with narcolepsy. Journal of Clinical Sleep Medicine. 2021;17(4):621-627.

8. Qiu J, Shen B, Zhao M, Wang Z, Xie B, Xu Y. A nationwide survey of psychological distress among Chinese people in the COVID-19 epidemic: implications and policy recommendations. General psychiatry. 2020;33(2).

9. Hawryluck L, Gold WL, Robinson S, Pogorski S, Galea S, Styra R. SARS control and psychological effects of quarantine, Toronto, Canada. Emerging infectious diseases. 2004;10(7):1206.

10. Shi L, Lu Z-A, Que J-Y, et al. Prevalence of and risk factors associated with mental health symptoms among the general population in China during the coronavirus disease 2019 pandemic. JAMA network open. 2020;3(7):e2014053-e2014053.

11. Gulia KK, Kumar VM. Importance of sleep for health and wellbeing amidst covid-19 pandemic. Sleep and Vigilance. 2020:1-2.

12. Altena E, Baglioni C, Espie CA, et al. Dealing with sleep problems during home confinement due to the COVID-19 outbreak: Practical recommendations from a task force of the European CBT-I Academy. Journal of Sleep Research. 2020:e13052.

13. Lange T, Dimitrov S, Born J. Effects of sleep and circadian rhythm on the human immune system. Annals of the New York Academy of Sciences. 2010;1193(1):48-59.

14. Zheng M, Yao J, Narayanan J. Mindfulness Buffers the Impact of COVID-19 Outbreak Information on Sleep Duration. 2020.

15. Li G, Fan Y, Lai Y, et al. Coronavirus infections and immune responses. Journal of medical virology. 2020;92(4):424-432.

16. Hajak Go, Group SS. Epidemiology of severe insomnia and its consequences in Germany. European Archives of Psychiatry and Clinical Neuroscience. 2001;251(2):49-56.

17. Morin CM, Carrier J. The acute effects of the COVID-19 pandemic on insomnia and psychological symptoms. Sleep Medicine. 2020.

18. Kocevska D, Blanken TF, Van Someren EJ, Rösler L. Sleep quality during the COVID-19 pandemic: not one size fits all. Sleep medicine. 2020;76:86-88.

19. Beck F, Leger D, Cortaredona S, et al. Would we recover better sleep at the end of Covid-19? A relative improvement observed at the population level with the end of the lockdown in France. Sleep medicine. 2021;78:115-119.

20. Yang Y, Zhu J-f, Yang S-y, et al. Prevalence and associated factors of poor sleep quality among Chinese returning workers during the COVID-19 pandemic. Sleep medicine. 2020;73:47-52.

21. Ernstsen L, Havnen A. Mental health and sleep disturbances in physically active adults during the COVID-19 lockdown in Norway: does change in physical activity level matter? Sleep Medicine. Jan 2021;77:309-312.

22. Baglioni C, Nanovska S, Regen W, et al. Sleep and mental disorders: A meta-analysis of polysomnographic research. Psychological bulletin. 2016;142(9):969.

23. Brzyski M, Hales M. The Effect of Physiological Stress on Melatonin Levels. 2020.

24. Gulia KK, Kumar VM. Sleep disorders in the elderly: a growing challenge. Psychogeriatrics. 2018;18(3):155-165.

25. Seol J, Abe T, Fujii Y, Joho K, Okura T. Effects of sedentary behavior and physical activity on sleep quality in older people: A cross-sectional study. Nursing \& Health Sciences. 2020;22(1):64-71.

26. Veronda AC, Irish LA, Delahanty DL. Effect of smoke exposure on young adults' sleep quality. Nursing \& Health Sciences. 2020;22(1):57-63.

27. Xiao H, Zhang Y, Kong D, Li S, Yang N. Social capital and sleep quality in individuals who self-isolated for 14 days during the 
coronavirus disease 2019 (COVID-19) outbreak in January 2020 in China. Medical science monitor: international medical journal of experimental and clinical research. 2020;26:e923921-923921.

28. Pallesen S, Bjorvatn B, Nordhus IH, Sivertsen B, Hjørnevik M, Morin CM. A new scale for measuring insomnia: the Bergen Insomnia Scale. Perceptual and motor skills. 2008;107(3):691-706.

29. Tuba Bay IY, Ayșe Ergün Validity and Reliability of Bergen Insomnia Scale in Adult Individuals. 1st International 2nd National Public Health Nursing Congress. Ankara: ISBN 978605-9278-54-6; 23-26 Nisan 2018

30. Demirer İ, Erol S. Üniversite öğrencilerinin fiziksel aktivite düzeyleri ile uykusuzluk ve psikolojik iyilikleri arasındaki ilișki. Psikiyatri Hemşireliği Dergisi. 2020;11(3):201-211.

31. Nishino S, Mignot E. Drug treatment of patients with insomnia and excessive daytime sleepiness. Clinical pharmacokinetics. 1999;37(4):305-330.

32. Voitsidis P, Gliatas I, Bairachtari V, et al. Insomnia during the COVID-19 pandemic in a Greek population. Psychiatry Research. 2020:113076.

33. Casagrande M, Favieri F, Tambelli R, Forte G. The enemy who sealed the world: Effects quarantine due to the COVID-19 on sleep quality, anxiety, and psychological distress in the Italian population. Sleep Medicine. 2020.

34. Ohayon MM, Sagales T. Prevalence of insomnia and sleep characteristics in the general population of Spain. Sleep medicine. 2010;11(10):1010-1018.

35. GAMSIZKAN Z, ASLAN S. Birinci Basamakta İnsomnia Sıklığı ve İlişkili İnanç ve Tutumların Değerlendirilmesi. Journal of Cognitive Behavioral Psychotherapy and Research. 2014;3:156-161.

36. Parlapani E, Holeva V, Nikopoulou VA, et al. Intolerance of Uncertainty and Loneliness in Older Adults During the COVID-19 Pandemic. Frontiers in Psychiatry. 2020;11:842.

37. Pizzonia KL, Koscinski B, Suhr JA, Accorso C, Allan DM, Allan NP. Insomnia during the COVID-19 pandemic: the role of depression and COVID-19-related risk factors. Cognitive Behaviour Therapy. 2021:1-15.
38. Bar M, Schrieber G, Gueron-Sela N, Shahar G, Tikotzky L. Role of self-criticism, anxiety, and depressive symptoms in young adults' insomnia. International Journal of Cognitive Therapy. 2020;13(1):15-29.

39. Suganuma N, Kikuchi T, Yanagi K, et al. Using electronic media before sleep can curtail sleep time and result in self-perceived insufficient sleep. Sleep and Biological Rhythms. 2007;5(3):204-214.

40. Brunborg GS, Mentzoni RA, Molde H, et al. The relationship between media use in the bedroom, sleep habits and symptoms of insomnia. Journal of sleep research. 2011;20(4):569-575.

41. Shneider A, Kudriavtsev A, Vakhrusheva A. Can melatonin reduce the severity of COVID-19 pandemic?

42. Cao X-L, Wang S-B, Zhong B-L, et al. The prevalence of insomnia in the general population in China: A meta-analysis. PloS one. 2017;12(2):e0170772.

43. McNamara JP, Wang J, Holiday DB, et al. Sleep disturbances associated with cigarette smoking. Psychology, health \& medicine. 2014;19(4):410-419.

44. Marjanovic Z, Greenglass ER, Coffey S. The relevance of psychosocial variables and working conditions in predicting nurses' coping strategies during the SARS crisis: an online questionnaire survey. International journal of nursing studies. 2007;44(6):991-998.

45. Reynolds DL, Garay J, Deamond S, Moran MK, Gold W, Styra R. Understanding, compliance and psychological impact of the SARS quarantine experience. Epidemiology \& Infection. 2008;136(7):997-1007.

46. Xiao H, Zhang Y, Kong D, Li S, Yang N. The effects of social support on sleep quality of medical staff treating patients with coronavirus disease 2019 (COVID-19) in January and February 2020 in China. Medical science monitor: international medical journal of experimental and clinical research. 2020;26:e923549-923541.

47. López-Moreno M, López MTI, Miguel M, Garcés-Rimón M. Physical and Psychological Effects Related to Food Habits and Lifestyle Changes Derived from COVID-19 Home Confinement in the Spanish Population. Nutrients. 2020;12(11):3445. 